\title{
Spatial Data Infrastructure Based Approach for Institutionalizing the Tenure Security in Alienated Government Lands
}

\author{
N.M.P.M. Piyasena*, R.P. De Silva ${ }^{1}$ and N.D.K. Dayawansa ${ }^{2}$ \\ Department of Surveying and Geodesy \\ Sabaragamuwa University \\ Sri Lanka
}

\begin{abstract}
Tenure security enables people to reap the benefits from land without any disturbances. As such, it is the basic element of sustainable economic, social and, environmental development. However, institutional inconsistencies between formal and informal institutions create the tenure insecurity in alienated government lands. The paper hypothesize that these institutional inconsistencies are mainly arise due to the fact that inefficient Spatial Data Infrastructure (SDI) provided by the surrounding organizational setup. The research investigates the significance of organizational setup in establishing the tenure security. Further, it explores the involvement of spatial data in the organizational issues that contribute to the development of insecurity of tenure. According to the investigation, bulk of the tenure security issues occurred due to the organizational inefficiencies and most of these organizational issues are related with the spatial data. Finally, the research has identified the matters to be dealt with, when institutionalizing a proper SDI within an identified organizational setup to enhance the land tenure security in alienated lands.
\end{abstract}

Keywords: Spatial data infrastructure, tenure security

\section{INTRODUCTION}

Secure tenure is the certainty that person's right to land is recognized by others and protected in case of specific challenge (FAO, 2006). Insecure tenure hinders good governance and the emergence of engaged civil society and increase the vulnerability of populations to disasters and environmental degradation. Without effective access to property, economies are unable to progress and the goal of sustainable development cannot be realized (UN-FIG, 1999).

Land tenure security issues in Sri Lanka starts to be intensified with the colonial ruling system for more than 200 years which encouraged the potential of land use towards cashcrop (tea, rubber, coconut) production. This has consequences in concentration of lands in the hands of Crown and thus in the hands of few foreigners. The population growth and its greater dependency on agriculture, made a complex problem of relationship, not only between individuals and land but also among the community as a whole (Singh, 1989). These factors together with other natural, socio-economic and political factors have further

\footnotetext{
Uva Wellassa University, Badulla, Sri Lanka

Department of Agricultural Engineering, Faculty of Agriculture, University of Peradeniya, Peradeniya, Sri Lanka

Author for correspondence: milinda@sab.ac.lk
} 
led to concentration of lands into the hands of government. According to a land policy report, almost $80 \%$ of the lands in Sri Lanka are controlled by the state itself (Wijethunga, 2004).

In order to establish effective state land tenure system, one of the main objectives of the government land policy reforming was to alienate the state lands to the landless as well as persons who are capable of developing such lands. Under this, authority has been given to the Land Reform Commission, Land Commission and the President himself to alienate the state lands. However, organizational arrangement under these provisions neither have a legal mandate nor interest to collect other necessary information such as land use and land type, extension and ownership verification, its potential of use, whether it involves with jurisdiction of any other authorities, etc. This has led to emergence of informal institutions in utilizing the land resources. Presently, intensive conflicts between formal and informal institutions are prevailing in these alienated lands. These institutional inconsistencies create the tenure insecurity (Piyasena, 2009).

Accordingly, the objective of the study is to identify the significance of Spatial Data Infrastructure (SDI) in land tenure insecurity issues and bring forth appropriate policy alternatives in institutionalizing a proper SDI.

In the view of achieving the above objective a theoretical review has been done to define a framework to analysis the land tenure system in terms of secure tenure elements that need to be accomplished in establishing the land tenure security in alienated lands. This review has also led to determine a configuration of a SDI model that could facilitate a greater interoperability among organizations.

\section{Theoretical review}

\section{Analysis of a land tenure system}

Land tenure mainly consists of property rights and relations originating thereafter. As such, it can be defined through institutions. According to North (1991) institutions are humanly devised constrains that structure political, economic, and social interactions. Throughout the history, institutions have been devised by human beings to create order and reduce the uncertainty in exchange (North, 1991). Land tenure system consists of formal, informal, and customary institutions which define the accepted means of various human relations originated through the interests of individuals and groups with related to the land based resources. These relations can be categorized into two: interests of individuals related to the land and resulting relations and interests of organizations related to the land and resulted relations (Piyasena, 2009). Table 1 illustrates the major elements of secure tenure.

\section{Table 1. Secure tenure elements and their attributes}

\begin{tabular}{ll}
\hline $\begin{array}{l}\text { Secure tenure } \\
\text { element }\end{array}$ & Objectives and factors need to be concerned \\
\hline Duration of rights & $\begin{array}{l}\text { Objective: Increase the security of investment } \\
\text { Duration should be equivalent to the possible investment may } \\
\text { accrue or more than that, rights need to be inherited, women's } \\
\text { ability to control land on their own }\end{array}$ \\
Methods of & Objective: Easy to identify and exchange
\end{tabular}


Piyasena et al.

\begin{tabular}{ll}
$\begin{array}{l}\text { demarcation and } \\
\text { transfer }\end{array}$ & $\begin{array}{l}\text { Identification of land, recoding of transactions (low and high } \\
\text { accuracy depending on the purposes) }\end{array}$ \\
$\begin{array}{l}\text { Enforcement } \\
\text { institutions }\end{array}$ & $\begin{array}{l}\text { Objectives: call on the power of estate or any other institution in } \\
\text { case of specific challenge (legal backing and social legitimacy) } \\
\text { The gap between legality and legitimacy }\end{array}$ \\
Subject of rights & $\begin{array}{l}\text { Objective: Policies of distribution of land rights } \\
\text { Individuals or groups }\end{array}$ \\
$\begin{array}{l}\text { Evolution over } \\
\text { time }\end{array}$ & $\begin{array}{l}\text { Objectives: From group rights to individual rights } \\
\text { Land conflict resolution due to the scarcity of land resources. } \\
\text { Protection of poor and vulnerable }\end{array}$ \\
\hline
\end{tabular}

Adopted by (Deininger, 2003)

The above elements can only exhibit their mandate through a well arranged organizational setup and legal background. The organizational side must be attributed with low cost means of efficient and effective services, easy means of access with well defined and less bureaucratic procedures. On the other hand, legal side should be attributed with well defined land rights and the mean of acquiring such rights. These will in turn provide functional certainty and security of the law and human rights, public participation in decision making, accountability of institutions which are the base for functioning of land market with intensive land investments. In order to build such environment, it is utterly important to identify the indication for existing degree of land tenure security. According to this study, the degree of consistencies within and among these institutions defines the degree of tenure security (Piyasena, 2009). Hence, it is extremely important to identify the ontology behind the creation of institutional inconsistencies, which in turn can be defined as the land tenure insecurity.

\section{Spatial data infrastructure}

The attributes defined through the spatial data are drastically changed with the purpose and the organizations involving with data collection. However, their potential for multiple uses for different purposes is unchallenged. As such, integration of different data sets brings new insight which can be used for entirely different purpose to the data originally collected (Groot \& McLaughlin, 2003). The above potential of spatial data urged the need of proper infrastructure facilities so that different data sets could be integrated to create new insights which can be used in some other purposes than what they originally collected. Hence, the new concept of SDI has been immerged. In general, SDI can be referred as enabling effective access to the spatial data. However, in broad definition it is the networked geospatial databases and data handling facilities, the complex of institutional, organizational, technological, human, and economic resources which interacts with one and another and underpin design, implementation, and maintenance of mechanisms facilitating the sharing, access to, and responsible use of geospatial data at an affordable cost for a specific application domain or enterprises (Groot \& McLaughlin, 2003). 


\section{Main characteristics of SDI}

\section{Spatial data quality}

Spatial data quality is defined by the factors such as lineage, consistency, completeness, semantic accuracy, temporal accuracy, positional accuracy, and attributes accuracy (Groot \& McLaughlin, 2003).

\section{Legal perspectives of SDI}

A proper legal framework needs to be established in order to avoid laps and gaps in responsibility of spatial data handling as well as protect the privacy to reap the benefit of technological advance.

\section{Standards}

Standards are useful in portability, inter-operability and information access and maintainability of spatial data (Groot \& McLaughlin, 2003)

\section{Interoperability}

Geospatial database is mainly the computer representation of real world structure. The heterogeneity problem occurs when different communities waiting to share their data with each others whose having different perspectives of the real world objectives. The heterogeneity issues can be syntactic, schematic, and semantic heterogeneity (Groot \& McLaughlin, 2003).

Syntactic heterogeneity refers to different software and hardware platforms, database management systems, and the representation of geospatial objects (Vector Raster images, coordinate systems, quality of geometric representation, methods of data acquisition etc.). Schematic heterogeneity refers to the differences in database models or classes in difference databases, or an object in one database may be considered an attribute in another subject. Semantic heterogeneity refers to the meaning of real world entity within a database. It may intimately tie to the application context or discipline for which the data is collected and used (Groot \& McLaughlin, 2003).

\section{MATERIALS AND METHODS}

\section{The study area}

Under the provision of Land Development Ordinance (LDO) the Kalthota Colony in Rathnapura district was established in 1959. Originally, the area was divided among 206 families according to the rules specified in the ordinance with the ceilings of 5 acres for paddy lands and 3 acres of high lands for each allottee. These lands were restricted with minimum subdivision of half acres. The total area of the scheme consists of six villages namely; Paspalagama, Munwatha Kalegama, Kolonmadagama, Elaudalandagama, Budhugala, Uggal kalthota. Allottees of such lands fall into four categories namely; land given to those whose lands were acquired by the government for the requirement of the colonization project, landless people within the district that the project was conducted, 
laborers who have worked at least 500 day for the project and landless from crowded areas away from the colonization scheme (MLD \& MEA).

\section{Tenure security issues in the case study area}

The titles given under LDO mainly consist of restricted tenure system where such holder restricted in sell, lease, mortgage or otherwise without permission from Divisional Secretary as well as use the lands for other than the given purpose (i.e. paddy cultivation). According to the policy objectives behind the ordinance, upon the successful maintenance of land the lands by the allottee, that is, taking of appropriate conservation measurements and successfully maintaining the annual due payments, the allottee entitles to upgrade his right to soil (MLD \& MEA).

Paddy cultivation is the main land use in the Kalthota colonization scheme and labor sharing system named Attham has been intensively used due to the reason of intensive labor cost. However, due to the reason of demographic change, presently, the Kalthota colony is experiencing a formation of informal tenure system. This informal tenure system consists of outsiders who informally acquired the land from the initial settlers and their descendants, encroachers of state lands as well as co-ownership of lands decent from parents (Piyasena, 2007). The allotments owned by the outsiders do not care about the rules imposed by the government and this has been possible due to the poor monitoring of Government authorities. Further, occupants of such lands even have deeds for their parcels due to the reason of long practice of the informal holding. Most of these holders do not practice agricultural activities but engage in business work and other form of wage earning work, hence violating the rules specified by the ordinance. Further, they have also violated the inheritance rules by dividing the land below the minimum allowed size. This has caused many social problems within a family unit as only one child can legally hold the rights to such land parcel. However, they face intensive conflicts when they confronted with formal system in such situations as when the need arises to mortgage the land for a development purpose. Further, even though some have informally prepared deed for them, the land values are condemned in front of outsiders due to the question of their validity (Piyasena, 2007).

The formal land owners face further difficulties due to the restriction of being unable to use the land for its potential. Restrictions to mortgage have further confined maximum economic use of the land according to the ability of the holders. These reasons have mainly caused poor livelihood conditions in the area. The area is also attributed with many co-owned lands where several descendants of the original holder's land is shared with. These co-owners are unable to claim the title for the land that they use mainly due to the reason of restriction imposed by ordinance over division of such lands. This is not only an economic problem but also a social problem as well.

The encroaches of state land face even worse situation than the formal land holders and others due the pressure from respective government authorities. Their request to formalize their rights from the Divisional Secretary and other respective authorities are rarely being addressed. This has lead to high transaction costs, including briberies, delay and inappropriate political interventions, in acquiring such rights.

Finally, rules which have imposed originally by the LDO have become unrealistic to the present socio-economical conditions and they are further hindering the potential of the lands for their maximum economic use. Hence, the public request is to allow them to access the government lands in wide and equitable base, with specific provision of safety nets for 
vulnerable groups. This may lead to effective land management with investments in housing, agriculture, industry, commerce, tourism and recreation needs within the prevailing enforcement pull factors.

\section{Data collection}

Data collection was carried out through structured and semi structured questionnaires with villagers in the study area and experts within the organizations identified in the study. The questionnaire focused on the farmers' consistencies with the secure tenure elements, namely; duration of the land rights, boundary demarcation and transferability of land rights, properties of enforcing institutions of such rights, fulfilling and secure the rights subject to socio-cultural demand and evolution of rights subject to new cost and benefit conditions. The questionnaire for the organizations focused on the vision and mission of the organization, issues faced in land alienation process such as verification of the size of the land and ownership, suitability of the lands for alienation, identifying people to provide lands etc. While focusing on these issues, it was attempted to identify how these selected institutions collect, store and manage data within the requirements of the elements of SDI.

It was attempted to identify the land tenure issues that villagers confronted with the identified organizational setup over the fulfillment of the secure tenure elements and their significance compared with other tenure security issues. In order to identify the significance in fulfilling the secure tenure elements by the organizational setup, the weight given by the villagers over the issues were used. Next, analysis was made to identify the degree of involvement of spatial data in organizational matters in fulfilling the secure tenure elements of villagers. For this purpose, weights obtained from the organizations over the issues that they faced in fulfilling the secure tenure elements were used. This analysis has led to identify the significance of SDI in establishing the tenure security and aspects need to be focused for future improvements

\section{RESULTS AND DISCUSSION}

\section{Organizational contribution in tenure security issues}

According to the averaging weight given by the villagers over the tenure security issues, the bulk of the cases $(81 \%)$ are resulted due to organizational matters (Fig. 1). However, one cannot forget that almost $19 \%$ of the issues are resulting due to the non organizational matters. These issues are mainly caused by not having a build-up of positive informal institutions to prevent unjustifiable personal interventions in decision making over the duration of rights and lack of proper agrarian culture for enforcing the tenure rights that they enjoying and preventing the free rider effect.

Villagers mainly have tenure security issues that need to be negotiated with Survey Department, Land Commissioner Department, and Divisional Secretary. Table 2 has summarized the organizational and non organizational tenure security issues that villagers have to deal with related to secure tenure elements. 


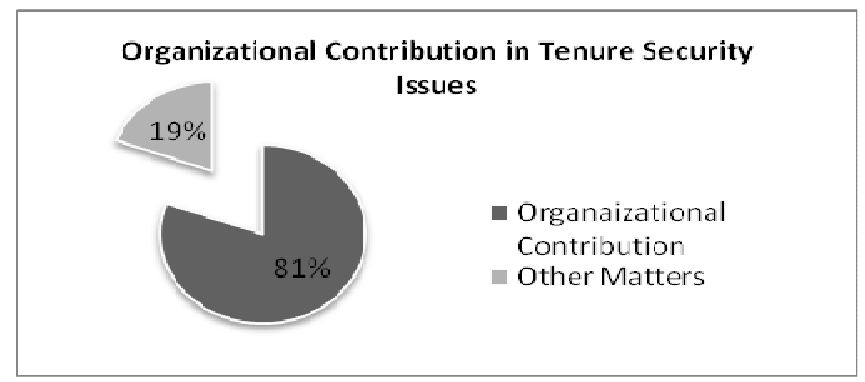

Fig. 1. Contribution of organizations on tenure security issues

Table 2. Involvement of organizations for establishing the tenure security in alienated lands

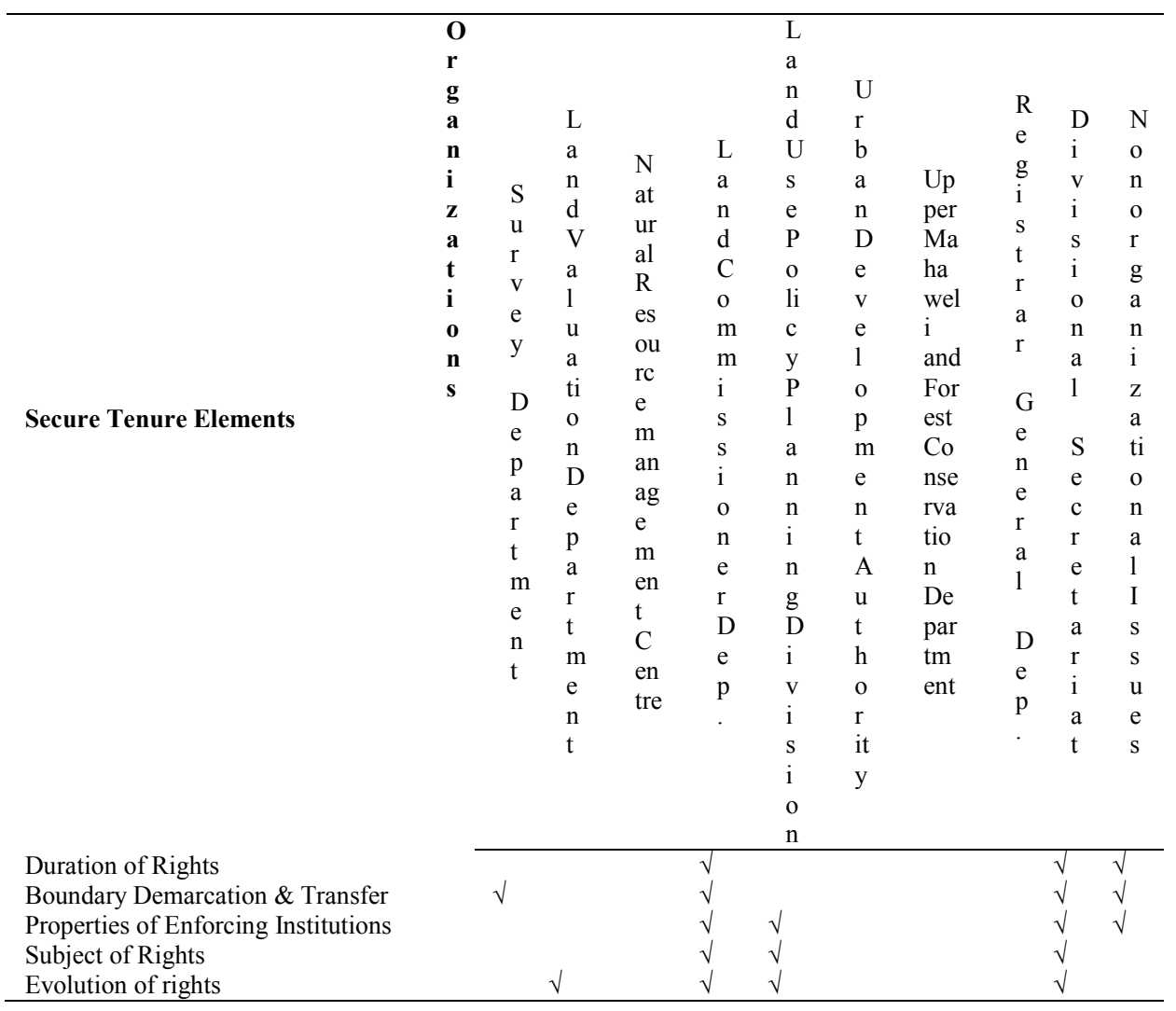

$\sqrt{ }$ - Issues Exist

\section{Contribution of spatial data in organizational issues}

Table 3 summarizes the inter-organizational matters those are related to creating the tenure security issues in fulfillment of its elements on the ground. It has also included the involvement of spatial data on each issue. According to the table, spatial data has involved in almost all the issues. 
Spatial data infrastructure based approach for tenure security in lands

Table 3: Organizational issues in fulfilling the tenure secure elements

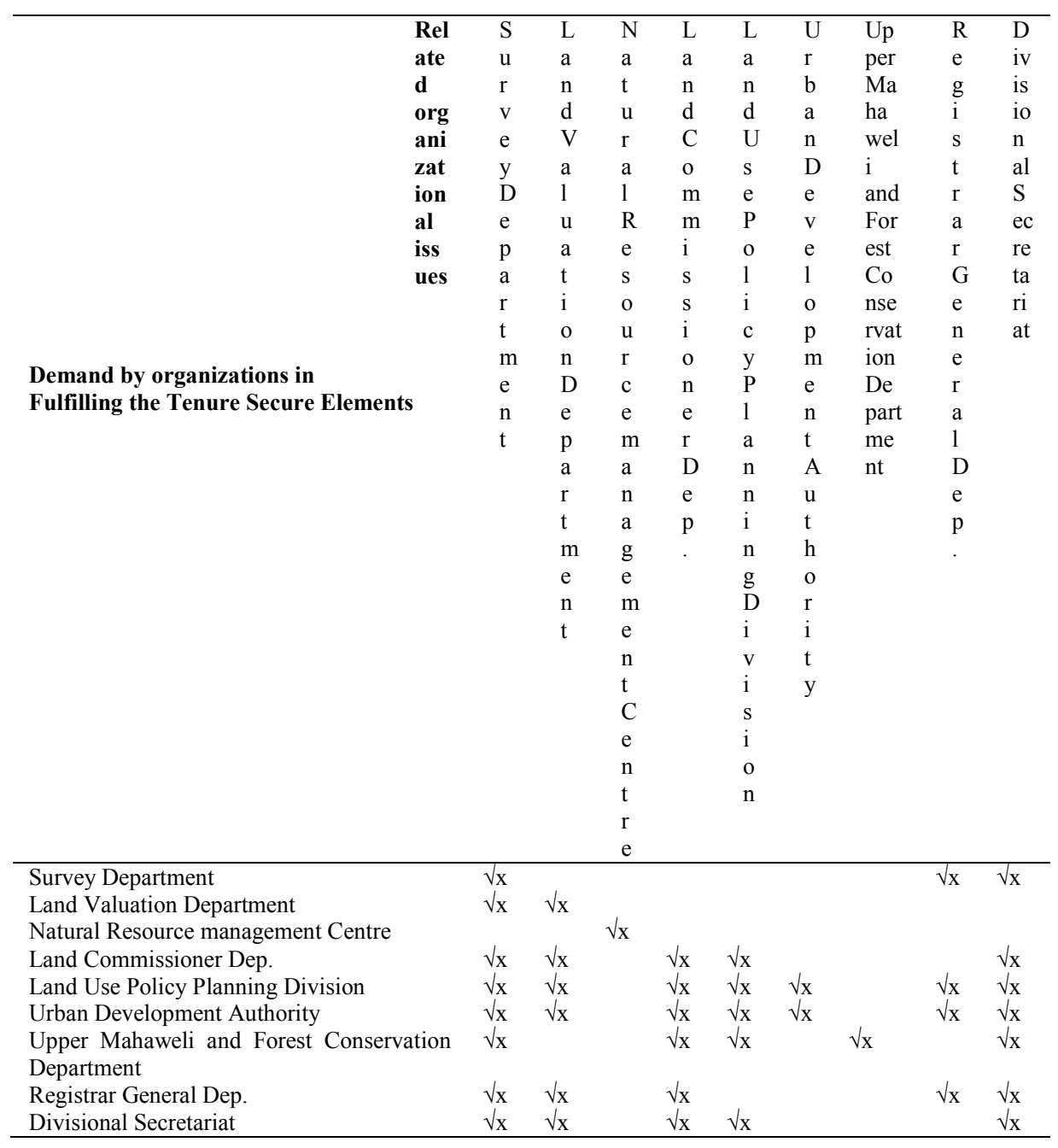

$\sqrt{ }$ - Issues Exist, $\mathrm{x}$ - Spatial Data Related Issues

The Fig. 2 illustrates the summarized view of the weighted values obtained from the answers to the questionnaire for the spatial data involvement in organizational related issues. 


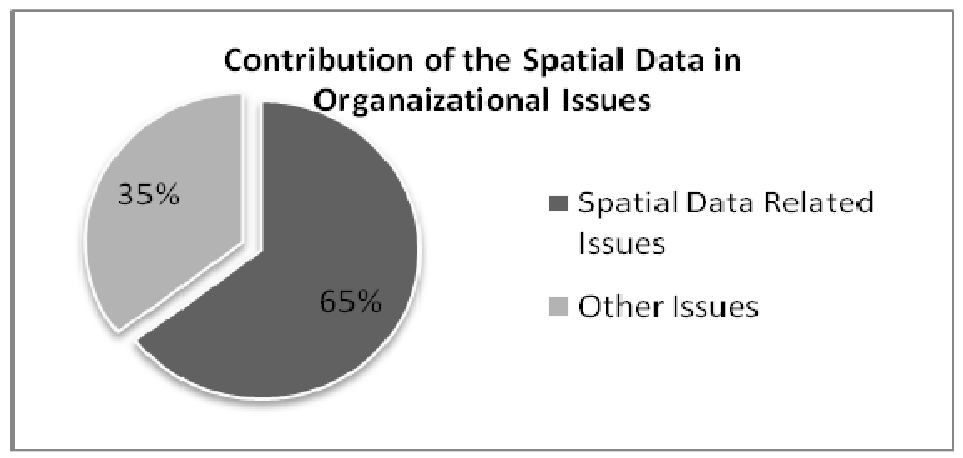

Fig. 2. Contribution of the spatial data in tenure security issues

The organizational issues, shown in Table 1, are mainly arising due the reason that most of the government organizations are unable to realize the ground truth conditions. This has further contributed to the under-utilization of the government lands and design of unrealistic development projects in the area concerned. Due to this inefficient decision making process, people tend to resort to informal means to satisfy their needs. Presently these informal institutions are much dominated in the colonization scheme. These informal utilizations of the scheme lands are almost impossible to reverse and they have created an intensive conflict between formality and legitimacy. This has confirmed by the Figure 1 [or Fig. 1].

According to the (Fig. 2) most of the issues related to organizations are based on spatial data. This result clearly highlighted the important of SDI based approach for tenure security issues. According to the study, it has been revealed that in most cases it is not the technological issues (as one would expect) that contributes to the inefficiencies in SDI but the issues related to the mechanism that has been established. In the ground level, Divisional Secretariat needs to be act as the hub of flow for the information between data providing organizations and decision making organizations. However, Divisional Secretariat does not play its role efficiently. Further, to make a realistic decision over development project within the colonization schemes, Divisional Secretary and the Land Commission need to have updated details of the boundaries and ownership. To this end inefficient data updating by the Survey Department is also problematic. The other main spatial information provider in this regard supposes to be the Land Use Policy Planning Division (LUPPD). However, it does not have the responsibility and capacity to provide the expected data. Basic data available in LUPPD for the decision making on land utilization suitability such as slope of the land, soil type, and land use land cover are much needed. Further spatial data providing organizations such as Survey Department, LUPPD, National Building Research Organization (NBRO), and Urban Development Authority (UDA) do not have proper coordination among each other to share the experiences and data. As such, same work needs not to be repeated several times.

\section{CONCLUSIONS}

A significant amount of tenure security issues $(81 \%)$ faced by the people live in the case study area are resulting due to the organizational inefficiencies. These organizational inefficiencies are mainly originating from Survey Department, Land Commissioners Department, and Divisional Secretary. According to the outcomes from the study, most of the organizational inefficiencies $(65 \%)$ are resulting due to lack of proper Spatial Data Infrastructure system. Hence, following policy alternatives within the identified role of appropriate organizations can be useful to establish a proper SDI. 
Survey Department needs to be the main spatial data provider in efficient and sustainable land alienation. Land Valuation Department has to play a vital role in land alienation as it is the only organization capable in predicting the potential economical use of a particular land parcel. These data are much needed to derive effective and efficient rules for land utilization in alienated lands. Overlapping responsibilities between NBRO and LUPPD need to be differentiated and LUPPD need to hold the responsibilities of providing the spatial data related to appropriateness of land utilization. However, the capacity of this organization need to be further developed. Land Commissioner remains responsible for making decisions over the state lands. However, it need to have legal binding in use of appropriate recommendations from LUPPD and use Survey Plans before making justifiable decisions over the land alienation. Role of the Registrar General needs to be improved to guarantee the title over private lands. This will eliminate the utilization of government land other than for the specified purpose. In order to keep above organizations functional, the Divisional Secretary's office should act as a hub for coordinating spatial information.

\section{REFERENCES}

Deininger, K. (2003). Land Policies for Growth and Poverty Reduction (New York : Oxford University Press.

FAO, United Nations' Food And Agriculture Organaization (2006). Land Tenure and Rural Development. FAO. [Online] [United Nation, December 02, 2006]. [Cited: December 02, 2006.] http://www.fao.org/DOCREP/Y4307E/y4307e05.htm.

Groot, R. and McLaughlin, J. (2003). Geospatial Data Infrastructure. New York : Oxford University Press.

MLD \& MEA, Minstry of Land Development and Minor Export Agriculture. Report on the study of land tenure in the Kagama-Kattiyawa Colony. s.l. : Sri Lanka Titling and Related Services Projects.

North, D.C. (1991). Institutions. The Journal of Economic Perspectives. Vol. 5, 1.

Piyasena, N.M.P.M. (2007). Institutional Arrangement and Land Tenure Development In Sri Lanka. s.l.: Unpublished M.Sc. thesis.

Piyasena, N.M.P.M. (2009). Analytical Framework for Institutional Contribution in Land Tenure Reforms. Nordic Journal of Surveying and Real Estate Research. , Vol. 6.

Singh, K. (1989). Land Reforms in South Asia, A Study of Sri Lanka. New Delhi : South Asian Publishers.

UN-FIG, United Nations and International Federation of Surveyors (1999). The Bathurst Declaration, UN-FIG International Workshop on Land Tenure and Cadastral Infrastructure in Support of Sustainable Development. www.sli.unimelb. [Online] 1999. [Cited: December 02, 2006.] http://www.sli.unimelb/edu.au/UNConf99/Proceedings.html.

Wijethunga, A.A. (2004). Proposed Land Policy Framework For Sri Lanka . s.l. : unpublished. 